\title{
Adapting urban areas for people with limited mobility
}

\author{
Ekaterina Melnikova, Mikhail Lepert, Aleksey Popov ${ }^{*}$ and Tatyana Sorokoymova \\ Moscow State University of Civil Engineering, Yaroslavskoe shosse, 26, Moscow, 129337, Russia
}

\begin{abstract}
In article the ways of adaptation of elements of improvement, and also replacement of monolithic and stationary parts of the equipment on flexible, transformed designs were analyzed. The main prerequisites for a qualitative change in the urban environment are the actual needs of the population: unhindered access to the objects of the mass service system (hereinafter MSS), safe movement on transport and pedestrian routes from residential areas to gravity focuses, the possibility of orientation, barrierfree communication and communication with dispatching service organizations in emergency situations through multimedia resources [7]. The main methods of research in the current article are full-scale surveys, interviewing the target audience with a preliminary sample. The article considers a set of solutions for the adaptation of the territory to the needs of PWLM by means of transformable structures [17]. Standardization of structures and equipment will allow to achieve better quality, more ergonomic solutions in the equipment of objects of different categories and purposes, unification of prefabricated elements-their serial production with the state control of products. Such organization of improvement will allow to achieve sustainable development of urban areas for the project period, will create a basis for future generations.
\end{abstract}

\section{Introduction}

The article describes the methods of implementation of the approach of complex interaction of different population groups in the framework of the concept of "barrier-free environment". The subject description of the elements of the interior and exterior entourage of ordinary buildings, public spaces and campuses were considered in accordance with the main objectives of the extensive development of urban areas [9-10].

The summary characteristic about the functional zone or object, elements of improvement consists of individual parameters of convenience, criteria of availability of the environment for the user, mobility and unification of elements of adaptation for the purpose of free use of them $[1-4,15-16]$. To ensure a comfortable stay in the city of large masses of the population, without loss of useful space in the arrangement of elements of improvement both in specific buildings and structures, and in public areas, should be guided by the principle of "From the Private to the General"[14].

\footnotetext{
* Corresponding author: da945@yandex.ru
} 


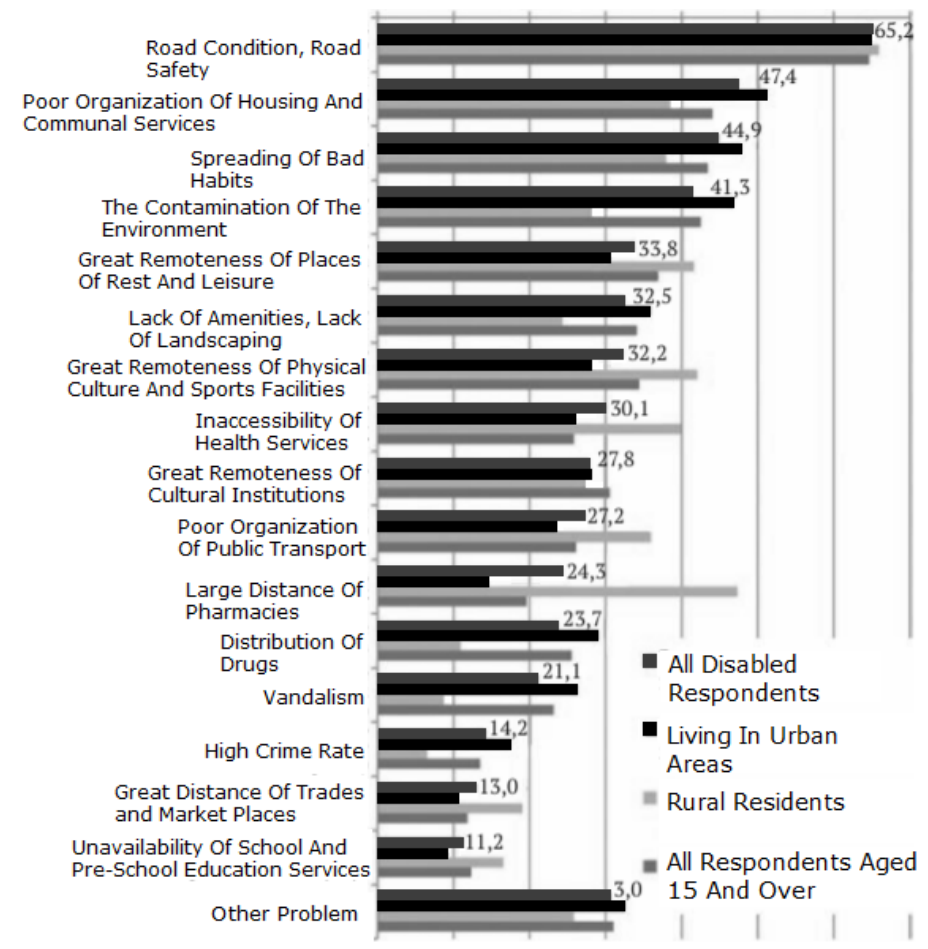

Fig. 1. Summary assessment of typical problems related to living conditions, according to respondents, \%. Source: Comprehensive Observation of the Life of the Population -2014 [11-13,18]

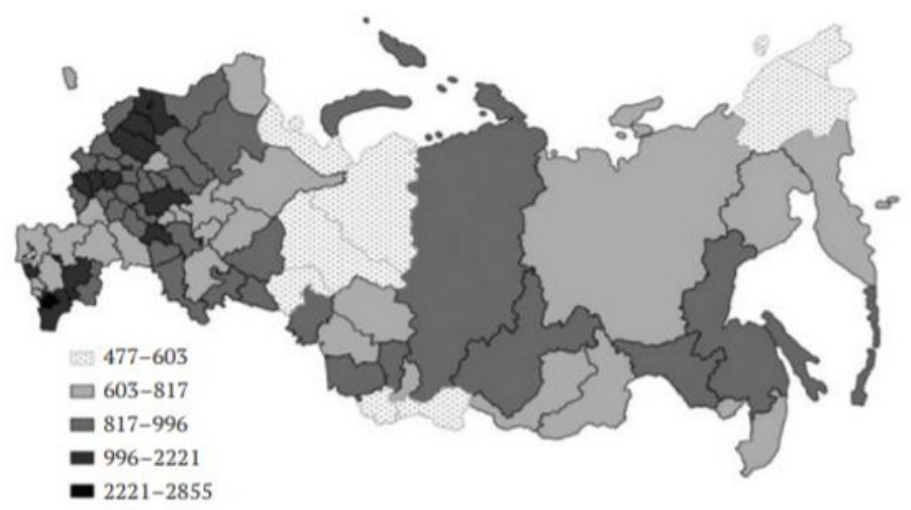

Fig. 2. The standardized disability rate per 1,000 people, according to the 2015-2016

World statistics on people with limited mobility reveals a continuous increase in the share of such citizens (official data of the World Health Organization for 2018 [5-6]) in the territory of our country, which predetermines the vector of urban development policy, exacerbates the problem of integration of the disabled population, and forms new approaches, the way of life of society (Fig. 1-2).

Although compared to other countries (Fig.3) in the Russian Federation, the percentage of disability (excluding other social groups belonging to the PWLM) is less, this group of 
the population is more than $9 \%$, which means that ensuring the comfort and safety of their residence in urban and rural settlements is an important state task.

\begin{tabular}{|c|c|}
\hline $\begin{array}{l}\text { FINLAND } \\
\text { UNITED } \\
\text { KINGDOM }\end{array}$ & 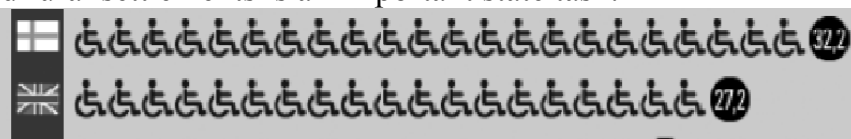 \\
\hline NETHERLANDS & 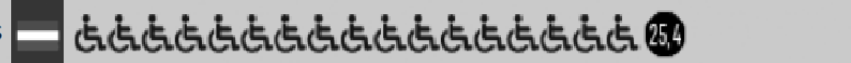 \\
\hline FRANCE & I \\
\hline ESTONIA & = \\
\hline $\begin{array}{l}\text { CZECH } \\
\text { REPUBLIC }\end{array}$ & - \\
\hline PORTUGAL & 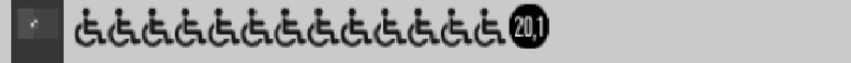 \\
\hline DENMARK & + E் \\
\hline SWEDEN & + \\
\hline $\begin{array}{l}\text { RUSSIAN } \\
\text { FEDERATION }\end{array}$ & — \\
\hline
\end{tabular}

Fig. 3. The fraction of disabled people in Europe, $\%$ of the population. Source: Eurostat, Ministry Of Public Health [11, 19-20]

\section{Methods}

When the process of studying the state of the territory and the environment, urban analysis, is on, the main methods of research are surveys (on various parameters, including the geological structure of soils, identifying areas and fixing the status of land plots, the location of communications, the composition of coatings, etc.). In addition, the popular ones are visual and full-scale recording, aerial photography, socio-demographic monitoring (face-to-face/correspondence survey, interviewing), continuous, one-time and coupon surveys, statistical and prognostic methods, modeling.

The survey was conducted using a questionnaire, which listed the main qualitative characteristics of the environment and improvement. A ten - point system for assessing the results was allocated: the low rating indicated a negative attitude of the population, the average assessment expressed a neutral attitude of the Respondent, the highest score-a sufficient degree of development of the territory, positive trends in the progress of this item (for example, comfortable equipment of quiet places, etc.).

As reference data for research, development of concepts of application of the transformed elements of improvement the updated parameters and characteristics of the UN development Program (UNDP), the summary data received at independent interviewing of inhabitants of standard residential areas of Moscow and the Moscow region are used (monitoring was carried out within 10 days in 10 quarters; the total sample made 200 people). 


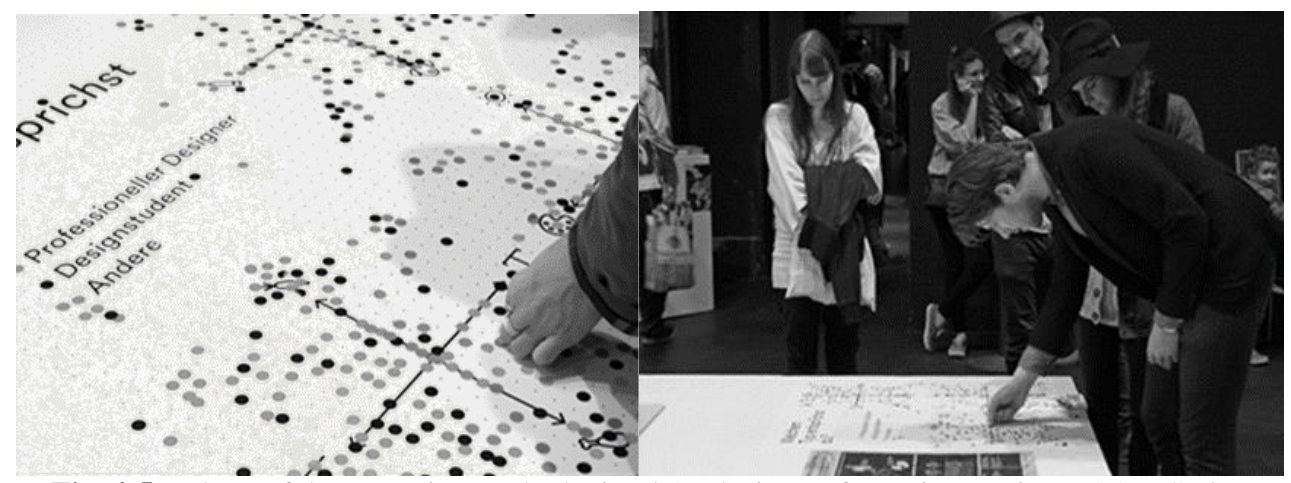

Fig. 4-5. Photo of the surveying method Visual Analysing. Information Design YAAY GmbH

\begin{tabular}{l} 
CITIZENS WITH PRAMS \\
\hline TEMPORARILY DISABLED \\
\hline CHILDREN UNDER 10 \\
\hline PREGNANT WOMAN \\
FOREIGNERS AND PEOPLE WITH \\
LUGGAGE \\
\hline $\begin{array}{l}\text { PEOPLE WITH NO MOBILITY } \\
\text { RESTRICTIONS, INCLUDING THOSE } \\
\text { WITH HEARING IMPAIRMENTS }\end{array}$
\end{tabular}

Fig. 6. Categories of the surveyed groups of the PWLM

Based on an independent assessment of the population (Fig 4-6), it was identified the main problems in the organization of safe pedestrian traffic, barrier-free movement in the territory, ensuring the comfort of use of social infrastructure:

-Non-compliance with the declared regulatory characteristics of the quality of structures;

- Moral and physical wear of structural elements and coatings (staircases, thresholds, dimensions of entrance groups);

- Lack of a convenient navigation system and a single colour scheme, unification of designations for better orientation in urban space;

- Seasonal factors that limit the possibility of using social services facilities (covering the slippery, the presence of areas with stagnation of storm water, watering, etc.));

-Lack of appropriate Parking signs and information stands, kiosks for visually impaired and hard of hearing groups;

- Missing or insufficient technical equipment of Hiking routes, playgrounds and quiet recreation areas for the needs of PWLM.

The solutions proposed in the article were developed by taking into account the normative legal acts and design standards established in the Russian Federation, as well as safety requirements.

Therefore, because of the population's requests and the shortcomings identified in the field survey to ensure a "loyal environment" were identified 3 main components that form the urban appearance and aesthetic appeal, the image of the place:

- Selection of small architectural forms and it's competent spatial arrangement;

- Equipment of pedestrian ways of communication, antiskid entrance groups, resistant to temperature extremes, corrosion-resistant coatings and materials;

- Availability of interactive information elements, visual and spatial dominants.

In addition, the organization of accessible urban environment mandatory parameters of modern architectural and spatial solutions, public spaces should be: focus on the 
compensation of health problems in the field of musculoskeletal system, Central nervous system, organs of vision. The main principle is the intensification of interaction between different groups of the population, the integration of persons with disabilities in all spheres of society.

\section{Results}

World In the scientific work carried out earlier (Adapting Elements Of Improvement For PWLM. Organization Permeable Urban Space) proposals for each of the selected areas were considered; the given article consider further application models and operational, comparative characteristics, description of the projected advantages of flexible transformable elements of improvement in practical use.

According to the first point, it is supposed to use "flexible" transformable, retractable structures in the improvement of the territory for PWLM. As the world design experience shows, auxiliary elements (handrails, ramps, holders for various purposes, rotary devices, pointers, etc.; Fig. 7), used in the construction of interiors, when used in the city not only provide convenience for people with limited mobility, but also are an important indicator of the quality of the environment (its investment attractiveness).

The compactness of such mechanisms allows to minimize the impact on the aesthetic perception of space, almost does not affect the perception of the facades of buildings and structures.

A technical example of the implementation of this method is the installation of embedded parts and fastening mechanisms in the niches provided for this purpose on the facade parts of buildings and structures, as well as ensuring the blocking of the opening of the door flaps in excess of the turning angles, which ensures comfortable and safe movement at the entrance groups. If necessary, the device is set to the design position by pressing (movement is performed independently PWLM).

The equipment and its elements can be painted in different colors: contrasting solutions emphasize individuality and conceptuality, simplify navigation, making the object visible to the PWLM; classical execution of elements with metal, including chrome surfaces will complement the construction of ordinary neighborhoods and commercial spaces.

As a response to the society's second request for convenient organization of pedestrian traffic, organization of permeable and safe environment, a specialized tactile anti-slip tile was proposed. Manufacturing feature of units of such road surface (tiles) is that in the prepared in advance non-removable polymer-form-casing is placed a mixture of concrete of the required grade with fractions of ceramic-granite stone as a filler, making the structure of the tile more resistant to loads due to the internal adhesion of particles. The tight compression by the rubber casing fixes the position of the elements.

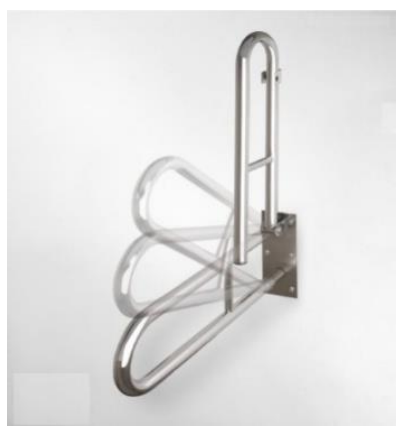

Fig . 7. Transformable architectural forms

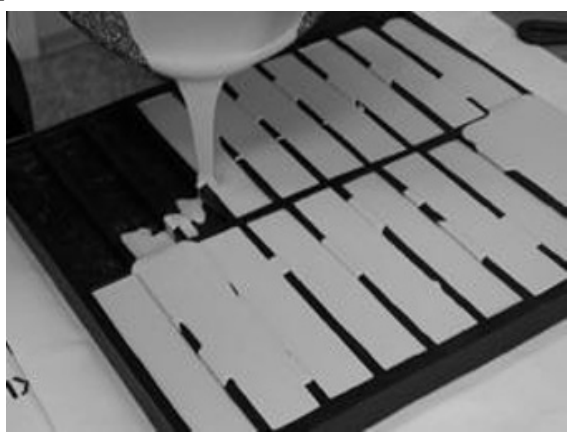

Fig . 8. Elements of equipment for pedestrian communications 
Individual seamless rubber coating is not only the optimal corrosion protection for each mounting element, but also an excellent insulating agent (used against stray currents, as waterproofing). Also, the material shows excellent quality in shape recovery (the outer layer is made of self-healing rubber made by the technology of the Higher school of industrial physics and chemistry (ESPCI, Paris [8-9], Fig. 8): unique in its properties, the rubber is able to recover from pieces into a whole cloth, after the break; connection is possible only on the surface of the break or cut). The structure of the tile prevents slipping, is a poor conductor of electric current, which has a positive effect on the overall safety of the objects. The tiles can also be used when facing stairs.

The comparative simplicity of the technological cycle allows to produce tiles of any size, color, configuration, with a slight increase in the cost of production.

Currently, stand-alone kiosks working on the system of processing user requests and issuing a limited amount of structured information are particularly popular in the formation of information-rich environment of the city. Also, in urban areas are actively used mimic diagrams and pointers.

It seems more promising to equip parks, public centres, transport hubs and other induction "pulse" panels, working on the basis of the neural network and "live database". The main difference is that the dynamically developing, self-learning database works in direct access to the Internet, and provides output information not only in the form of a graphical key, but also in the form of an audio signal, a touch-pulse code (it is possible to adjust the vibration level of the panel (similar to the volume of the speakers)).

The panel device provides an alternative biometric access, which provides maximum protection of personal data, availability of documents or other useful information for the user with connection of profile, public accounts of social networks, which simplifies the navigation system. Individual approach of using equipment (in the process of recognition thematic canvas selects the method of user interaction: vibration, graphic keys, etc.) provides the ability to group the queries according to the frequency of their repetition, and relevance, to remember the driving directions and maps on the "cloud storage", a make a quick translation of information and to switch the language settings, adaptive graphical mimic diagrams (Fig.9).

The considered technical solution (Fig.10) can be integrated into multifunctional spaces, in the form of stand-alone kiosks and subject panels on equipment, workplaces, co-working centers, small architectural forms, ticket offices, entrance groups and etc.

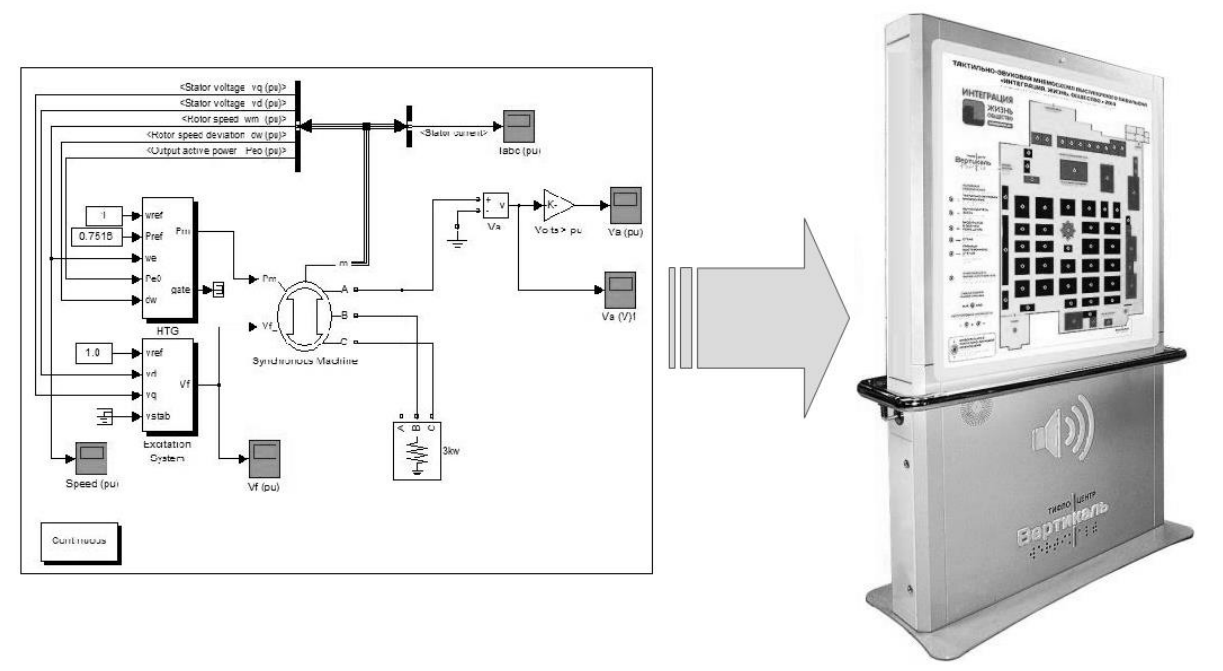

Fig .9. A software model of the information equipment 


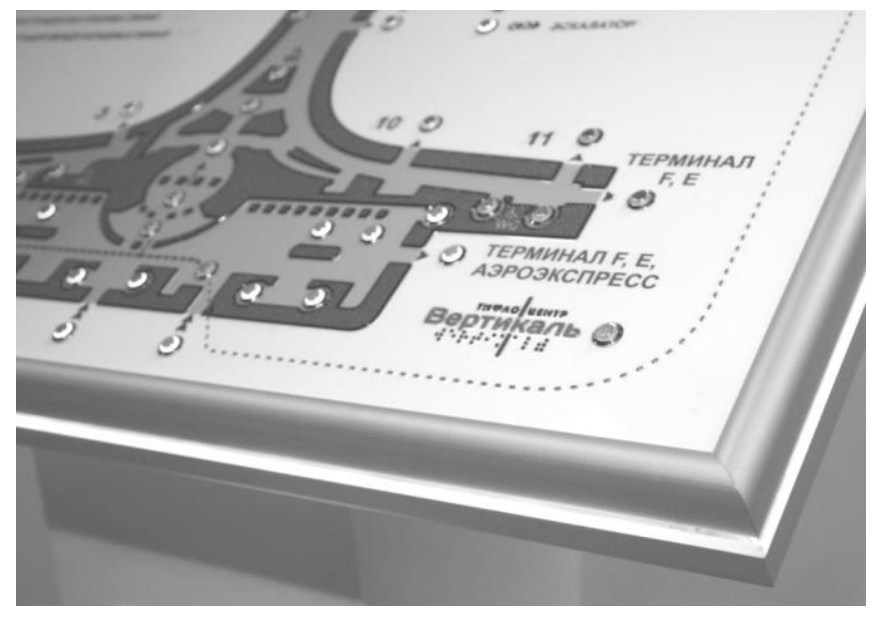

Fig . 10. A fragment of the working panel

The target audience will be able to get full information about the location, directions of movement, nearby routes and stops of land and non-surface transport, other sections.

\section{Discussions and conclusions}

The proposed approach to the use of transformable structures in the complex equipment of public spaces and residential areas in conjunction with the competent organization of safe pedestrian transit, traffic at the site will improve the accessibility of the environment and the safety of movement of people with limited mobility, including people with disabilities, in the infrastructure of the city. Based on the existing standards of urban design and accessibility for PWLM, the technical solutions considered in the article combine such "urban dimensions" as time (updating and adaptability of systems to the actual needs of the population and a specific technical task), scale and proportionality (elements of improvement in the context of the urban environment act as navigation components, provide permeability and ergonomic), eco-loyalty and unification (possibility of rapid replacement of equipment or its elements-links, processing and reuse of materials).

The difference characterizing the transformed structures expressed in the fact that the elements of improvement form an independent technical infrastructure of the city.

High-quality organization of public areas increases the investment attractiveness of objects, causes the influx of population and increased interest in the acquisition of residential areas.

High-quality organization of public areas increases the investment attractiveness of objects, causes the influx of population and increased interest in the acquisition of residential areas. Comprehensive adaptation of urban space to the needs of people with limited mobility, in turn, creates a tendency to change the General perception of urban areas, a vector for the complex development and unification of similar facilities and urban infrastructure.

It is necessary to continuously update the regulatory framework in accordance with the latest technologies and developments, both domestic manufacturers and leading foreign companies in the market.

Focusing on the creation of a barrier-free, interactive environment for PWLM at the design stage is one of the most important urban development tasks, the determinant of the development of cities and settlements. 


\section{References}

1. SR 59.13330.2016 Accessibility of buildings and structures for people with limited mobility [Text]. - Enter.2017-05-15.- M.: Publishing house of standards, LLC "Institute of public buildings", Association MOAB, NP "Accessible urban environment" (2017);

2. SR 35-105-2002 Reconstruction of urban development, taking into account accessibility for the disabled and other people with limited mobility [Text]. Enter.2002-07-19.- M.: publishing house of standards, GUP CPR (2018);

3. SR 35-101-2001 Design of buildings and structures, taking into account accessibility for people with limited mobility. General provisions [Text]. - Enter.2001-07-16.- M.: Publishing house of standards, sue "Institute of public buildings", (2001);

4. SR 35-102-2001 Living environment with planning elements accessible to persons with disabilities [Text]. - Enter.2001-07-16. - M.: Publishing house of standards, sue "Research and design Institute of educational, commercial, domestic and leisure buildings"(2001);

5. Official website of the World Health Organization (WHO) [Electronic resource]: Online journal/ Russia (2019). - Mode of access to the directory: https://www.who.int/topics/disabilities/en/;

6. Conference of United Nations to the Convention on the rights of persons with disabilities, Eighth session, New York [Electronic resource]: Online journal/Russia (2015). - Mode of access to the directory: http://www.un.org/disabilities/documents/COP/cosp8_report_r.pdf;

7. The recommendations of the Committee on the rights of persons with disabilities (CRPD) the UN [Electronic resource]: /Original: English, (2018); mode of access to the directory: https://perspektiva-inva.ru/protec-rights/oon/2018-05-04-09-09-09/;

8. Review of developments of the Higher school of industrial physics and chemistry (high school de Physique and Chemistry Industrielles was - ESPCI). Original article: journal of Nature. [Electronic resource]: Online catalogue -Russia(2008). - directory access mode: http: / / www.lookatme.ru/flow/posts/scientific-techno/58258samovosstanavlivayuschayasya-rubber;

9. A.V. Popov, International Journal of Civil Engineering and Technology (IJCIET) Historical Development Stages of the Student Youth Accommodation Architecture from Dormitories Prototypes to Post-industrial University Campuses 9(11), 2526-2536 (2018);

10. A.V. Popov, Advanced Materials Research Ecological Optimization of the Architectural Environment of Higher Education Institutions in Moscow - The Use of Phyto-Metal Structures 869-870, 162-166 (2014);

11. Printed edition RANEPA Disability and social status of disabled people in Russia [Electronic resource]: Online magazine/ Russia(2015). - Mode of access to the directory: https://www.ranepa.ru/images/insap/invalides.pdf.;

12. Burdak A. Y., Tyndik A. Measurement of disability and the situation of persons with disabilities: international and Russian approaches // Vestnik of NSUEM No. 1. P. 2243.(2016). ;

13. S. A. Vasin, M. Y., E. E. Grishina, M. A. Yeliseeva, and others. Organization and comprehensive monitoring of the situation of persons with disabilities in Russia in the light Of the UN Convention on the rights of persons with disabilities. Ranepa. M., (2014); 
14. K. V. Zenkov, Art and culture Shaping in environmental architecture 4 (28), 48-51. (2017);

15. International classification of functioning, disability and health. WHO. Geneva (2001). https://extranet.who.int/iris/restricted/bitstream/10665/85389/1/924454542X.pdf;

16. Ragozin, L. G., Vasin S. A., Eliseeva M. A., Burdyak A. Ya. and others. The Social position of disabled people in the Russian Federation subject to the provisions of the Convention on the rights of persons with disabilities. Preprint. M.: Russian presidential Academy of national economy and public administration (2014). Availableat SSRN. http://ssrn.com/abstract=2542198;

17. Shabunova A. A., Vagradov L. N. Accessibility of the urban environment for persons with disabilities // territorial development Issues. № 3 (13). P. 1-15. (2014);

18. E. Shcherbina and M. Slepnev Scientific Rev., The system of town planning regulations for sustainable development of territories 6, 240-244 (2016);

19. Barinova G. V. Disability as a social phenomenon of modern Russian society (social and philosophical analysis) [Electronic resource]: Online magazine/ Russia (2015). Mode of access to the directory: http://www.avtoref.mgou.ru/new/d212.155.08/Barinova/diss.pdf.;

20. Official website of Eurostat [Electronic resource]: Online magazine (2019) - Mode of access to the directory: https://ec.europa.eu/eurostat. 